\title{
Association of Dietary Inflammatory Potential (DIP) and Endothelial Function Biomarkers among Female Nurses of Isfahan Hospitals
}

\section{Mohammad Gholizadeh}

Tehran University of Medical Sciences

Ebrahim Falahi

Lorestan University of Medical Sciences

Ammar Hassanzadeh Keshteli

Isfahan University of Medical Sciences

Ahmadreza Yazdan Nik

Isfahan University of Medical Sciences

\section{Parvaneh Saneei}

Isfahan University of Medical Sciences

\section{Ahmad Esmaeilzadeh}

Tehran University of Medical Sciences

Ahmad Saedisomeolia ( $\nabla$ a_saedi@tums.ac.ir)

Department of Cellular and Molecular Nutrition, School of Nutritional Sciences and Dietetics, Tehran University of Medical Sciences, Tehran, Iran

\section{Research article}

Keywords: Dietary inflammatory potential, sICAM-1, endothelial markers, sVCAM-1, E - selectin

Posted Date: June 12th, 2021

DOl: https://doi.org/10.21203/rs.3.rs-555465/v1

License: (a) (1) This work is licensed under a Creative Commons Attribution 4.0 International License. Read Full License 


\section{Abstract}

Background. Dietary inflammatory index (DIP) is a new dietary index designed to evaluate individuals' diets. In addition, adhesion molecules are important biomarkers for assessing endothelium inflammation that they related to atherosclerosis and cardiovascular disease. Also, there is no study for assessing the association between adhesion molecules and DIP until now as well as other studies that assessed the relationship between dietary inflammatory index or DIP have controversy. The purpose of this crosssectional study was to determine the correlation between DII and endothelial markers such as E-selectin, intercellular adhesion molecule-1 (sICAM-1) and vascular cell adhesion molecule-1 (sVCAM-1) among female nurses from Isfahan. In this study, dietary inflammatory potential (DIP) was used instead of DII.

Methods: This study was performed on 420 healthy nurses. The nurses were selected by random cluster sampling method from private and public Isfahan hospitals. A validated food frequency questionnaire (FFQ) was applied to assess the dietary inflammatory potential. A fasting blood sample was collected for measuring the plasma levels of the endothelial markers and other variables.

Results: After adjusting different potential confounders, no statistical association was found between DIP and sICAM-1, E- selectin and SVCAM- 1 in model I ( $P=0.57,0.98$ and 0.45$)$, model II ( $P=0.57,0.98$ and $0.45)$ and model III $(P=0.67,0.92$ and 0.50$)$ in comparison to the crude group $(P=0.35,0.83$ and 0.49 , respectively).

Conclusions: The results revealed that the plasma levels of endothelial markers including E-selectin, sICAM-1, and SVCAM-1 were not significantly associated with DIP in female nurses.

\section{Introduction}

Atherosclerosis is a continuing inflammatory state of the vessels [1]. The progression of atherosclerosis leads to myocardial infarction and sudden death [2]. It is believed that atherosclerosis is an inflammatory condition that is largely responsible for cardiovascular disease (CVD) mortality [3, 4]. Endothelial dysfunction contributes to the pathogenesis of vascular disease and plays an important role in CVD as well $[5,6]$. Endothelial dysfunction is characterized by impaired activity of endothelial derived relaxant factors and increased activity of vasoconstrictor factors. However, cell adhesion molecules (CAM) including E-selectin, intercellular adhesion molecule-1 (sICAM-1) and vascular cell adhesion molecule-1 (sVCAM-1) accelerate atherosclerosis [4, 7-9].

Adhesion molecules are normally expressed by the endothelium. They also play a role in leukocyte rolling, firm adhesion, and transmigration. Furthermore, they are associated with a variety of pathophysiological processes and inflammatory disorders. Atherosclerotic lesions and fatty streaks increase the expression of sICAM-1, sVCAM-1, and P- and E-selectin on the human endothelial cells [10, 11]. E-selectin plays an important role in acute inflammation [12-14]. Moreover, sICAM-1 and SVCAM-1 are involved in chronic inflammation $[15,16]$. Leukocyte adhesion is an important component of some vascular diseases and atherogenesis. Leukocyte recruitment occurs in a multistep process and selectin, which is expressed on 
the activated endothelial cells, is involved in the initial rolling process of leukocytes $[12,17]$. The leukocyte surface has sites for selectin ligand [18]. $\beta 1$ and $\beta 2$ integrin are expressed on leukocytes and act as binding sites for SVCAM-1 or sICAM-1. Furthermore, selectin plays a role in the initial rolling process of leukocytes whereas SICAM-1 and SVCAM-1 mediate leukocyte arresting and firm adhesion [12, 18-20].

Dietary inflammatory potential (DIP) is a new dietary index designed to evaluate the individual's diets. DIP is a tool to assess the potential inflammatory and anti-inflammatory properties of a diet based on food elements. In this index, values of $+1,0$, and -1 indicate pro-inflammation, indifferent and antiinflammation reactions, respectively [21]. Actually, DIP is a resource to assess pro-inflammatory effects of food ingredients based on anti-inflammatory functions [21, 22]. DIP has been linked to a variety of systemic biomarkers such as interleukin 6 (IL-6), tumor necrosis factor alpha (TNF-a), C-reactive protein (CRP) and several metabolic diseases such as CVD, cancers, and diabetes. Many studies have found that DIP is associated with the risk of metabolic syndrome and cardiovascular diseases [23-28].

Many studies have reported a positive association between DIP and CVDs $[29,30]$. Due to the increase in the global risk of CVDs and related diseases in the world, it is important to find healthy dietary patterns with low inflammatory scores to tackle inflammation and CVDs. The purpose of this study was to determine the association between DIP and endothelial markers such as SICAM, sVCAM, and E-selectin in female nurses working in Isfahan hospitals.

\section{Materials And Methods Participants}

Four hundred and eighty healthy female nurses aged $>30$ years participated in this cross-sectional study. The participants were selected randomly from seven public and private hospitals in Isfahan, Iran. The female nurses with a history of diabetes, malignancy, infections, and CVDs were excluded. Furthermore, the subjects who did not complete the FFQ questionnaire were also excluded from the study. Finally, 420 nurses were enrolled in the study. The participants fill in a consent form based on Tehran university of medical sciences ethics rules for participating on this study.

The study protocol was approved by Tehran university of medical sciences (IR.TUMS.VCR.REC.1399.584).

\section{Blood sampling}

Blood samples were collected from the participants after 12 hours of fasting to measure the levels of endothelial markers, lipid profile, and fasting blood glucose. Then, the sample were centrifuged for 30-45 minute and frozen at $70^{\circ} \mathrm{C}$. The levels of SVCAM- 1 , sICAM-1, and E-selectin were measured using commercial ELISA kits (Biosource International and Bender MED Systems) according to the 
manufacturer's instructions. ELISA kits were also used to measure low-density lipoprotein (LDL) and highdensity lipoprotein (HDL).

\section{Dietary inflammatory score}

The method developed by Shivappa et al was applied to calculate the DIP scores of the diets. The Food Frequency Questionnaire (FFQ) was used to determine the dietary intake [21]. In the Iranian dietary pattern, 29 out of 45 items of DII are very common, including Macronutrients (energy, carbohydrates, fat, protein, fiber), Fat (cholesterol, saturated fatty acids (SFA), monounsaturated fatty acids (MUFA), polyunsaturated fatty acids (PUFA)), Water-soluble vitamins (pyridoxine, folic acid, niacin, thiamin, ascorbic acid and riboflavin). Fat-soluble vitamins (A,D and E), Minerals (iron, magnesium, zinc, and selenium), as well as caffeine, $\beta$-carotene, onion, garlic, pepper, and black tea [31]. Other DIP items that were uncommon in the Iranian dietary regimen were omitted form the list of FFQ.

The intake of the above dietary items was adjusted according to the daily energy intake [32]. A z-score was generated for all of the 29 items of the FFQ list for each participant. For each subject, the "standard global mean" was subtracted from the mean consumed food and divided by "global standard deviation". The global means and standard deviations were obtained by the method developed by Shivappa et al [21]. To decrease the skewness of the variables, the variables were converted to a centered percentile score. This score was then extended by the impact for every item [21]. The DIP scores of all foods were summed to calculate the overall score. More positive values indicated a higher inflammatory dietary potential.

\section{Assessment of other variables}

A computerized scale was used for weight measurement (to the nearest $0.1 \mathrm{~kg}$ ). The subjects were asked to wear light clothing with no shoes. The height was also measured on the same visit day. Finally, weight $(\mathrm{kg})$ and height $(\mathrm{m})$ were used to calculate the body mass index (BMI) according to the following formula: weight $(\mathrm{kg}) /$ height $(\mathrm{m})^{2}$.

The International Physical Questionnaire was used to evaluate daily physical activity [33, 34] as MET-hour per week. The factors such as education level, family size, and economic status were inquired from all the participants to determine their socioeconomic status. Moreover, covariate data including age, marital status, menopause situation, past medical history, smoking or medication/supplementation history were selfreported by all the participants.

\section{Statistical analysis}

The final analysis was performed on 420 individuals. Energy adjustment of the variables was carried out using the residual method. After completing the FFQ, the data were entered into an Excel datasheet and daily dietary intakes were compared using the IBM SPSS version 26 (IBM SPSS Statistics for Win, Armonk, NY) and Nutritionist IV (N4) software. Since there were three DIP groups (tertiles), one-way ANOVA was used for continuous variables including age, body mass index (BMI), weight, waist circumference, physical activity, and systolic and diastolic blood pressure, and Pearson's chi-square test 
was applied to categorical variables such as oral contraceptive (OCP) use, current corticosteroid use, menopause, marital status, overweight/obesity and socioeconomic status. Similarities between the energy intakes of the participants were adjusted by linear regression. Finally, the associations between DIP and E-selectin, ICAM, and VCAM in three tertiles was analyzed using ANCOVA.

\section{Results}

The mean \pm SD age of the participants was $34.44 \pm 7.27,34.59 \pm 6.8$ and $36.47 \pm 7.4$ years in the 1 st, 2 nd, and 3rd tertile, respectively. The demographic characteristics of the subjects are presented in Table 1. 
Table 1

characteristics of participants by tertiles of dietary inflammatory index intake (means \pm SD)

\begin{tabular}{|c|c|c|c|c|}
\hline \multirow[t]{2}{*}{ Variables } & \multicolumn{3}{|c|}{ Tertiles of energy by DIP } & \multirow[t]{2}{*}{ P-value ${ }^{a}$} \\
\hline & $\mathrm{T} 1=133$ & $\mathrm{~T} 2=134$ & $\mathrm{~T} 3=129$ & \\
\hline Age(years) & $36.47 \pm 7.4$ & $34.59 \pm 6.8$ & $34.44 \pm 7.27$ & 0.04 \\
\hline Weight(kg) & $63.0 \pm 8.7$ & $69.2 \pm 82.7$ & $63.2 \pm 10.32$ & 0.49 \\
\hline $\operatorname{BMI}\left(\mathrm{kg} / \mathrm{m}^{2}\right)^{\mathrm{b}}$ & $24.2 \pm 3.37$ & $24.0 \pm 3.80$ & $23.97 \pm 3.65$ & 0.85 \\
\hline WC(CM) & $81.02 \pm 9.91$ & $80.51 \pm 9.83$ & $81.04 \pm 10.82$ & 0.89 \\
\hline PA(MET-h/wk) & $60 \pm 79$ & $78 \pm 77$ & $95 \pm 101$ & 0.05 \\
\hline $\mathrm{SBP}^{1}(\mathrm{mmHg})$ & $108 \pm 1.04$ & $109 \pm 1.20$ & $107 \pm 1.24$ & 0.24 \\
\hline $\mathrm{DBP}(\mathrm{mmHg})$ & $71 \pm 0.88$ & $70 \pm 1.05$ & $68 \pm 0.97$ & 0.08 \\
\hline Current OCP use (\%) & 5.9 & 7.4 & 5.9 & 0.84 \\
\hline Current corticosteroid use(\%) & 1.5 & 2.2 & 0.7 & 0.67 \\
\hline Menopausal (\%) & 8.1 & 4.4 & 4.4 & 0.30 \\
\hline Married (\%) & 71.3 & 73.5 & 73.9 & 0.87 \\
\hline Overweight or obese (\%) & 37.7 & 36.9 & 43 & 0.55 \\
\hline Socioeconomic status (\%) ${ }^{c}$ & 24.4 & 34.7 & 22.3 & 0.34 \\
\hline High & 44.4 & 40 & 48.9 & \\
\hline Medium & 31.1 & 25.3 & 28.7 & \\
\hline \multicolumn{5}{|l|}{ Low } \\
\hline \multicolumn{5}{|c|}{$\begin{array}{l}\text { BMI: body mass index, WC: waist circumference, SBP: systolic blood pressure,DBP: diastolic blood } \\
\text { pressure, OCP: oral contraceptives }\end{array}$} \\
\hline \multicolumn{5}{|c|}{$\begin{array}{l}\text { a) Obtained from analysis of variance for continues variables and chi-square for categorical } \\
\text { variables. }\end{array}$} \\
\hline \multicolumn{5}{|c|}{$\begin{array}{l}\text { b) High socioeconomic status was defined based on educational level, income, family size, being } \\
\text { owner of the house or renting the house, house area, being owner of the car and number and kind of } \\
\text { the car(s), number of bedrooms, and determination of who was in charge of the family. }\end{array}$} \\
\hline c) Body mass index $\geq 25$ & & & & \\
\hline
\end{tabular}

The distribution of the DIP score between tertiles is shown in Table 2. Large differences in DIP scores were observed for fat (P-value:0.04), riboflavin (P-value $<0.001)$, folic acid ( $P$-value $<0.001)$, cobalamin $(P$-value $=0.005)$, ascorbic acid $(P$-value $<0.001)$, vitamin A $(P$-value $<0.001)$, beta carotene $(P$-value $<$ 
0.001), zinc ( $P$-value $<0.001)$, tea $(P$-value $=0.002)$, magnesium $(P$-value $<0.001)$, onion $(P$-value $<0.001)$, fiber (P-value $<0.001)$, caffeine $(P$-value $=0.03)$, SAFA $(P$-value $=0.02)$, and cholesterol $(P$-value $<0.01)$ between the tertiles. 
Table 2

dietary inflammatory index intake of participants after adjusted energy $($ mean $\pm \mathrm{SD})$

\begin{tabular}{|lllll|}
\hline \multicolumn{5}{c}{ Tertile of energy -energy adjusted DIP } \\
\hline Nutrients & $\mathrm{T} 1(\mathrm{n}=136)$ & $\mathrm{T} 2(\mathrm{n}=137)$ & $\mathrm{T} 3(\mathrm{n}=136)$ & P-value \\
\hline Protein & $124 \pm 98$ & $135 \pm 139$ & $102 \pm 99$ & 0.06 \\
\hline Fat & $103 \pm 17$ & $117 \pm 88$ & $102 \pm 21$ & 0.04 \\
\hline Carbohydrate & $338 \pm 59$ & $321 \pm 61$ & $335 \pm 71$ & 0.06 \\
\hline Thiamin & $3 \pm 2$ & $5 \pm 25$ & $2 \pm 2$ & 0.06 \\
\hline Riboflavin & $1.8 \pm 0.51$ & $1.6 \pm 0.39$ & $1.4 \pm 0.47$ & $<0.001$ \\
\hline Niacin & $18.9 \pm 3$ & $18.8 \pm 3$ & $18.4 \pm 5$ & 0.6 \\
\hline Pyridoxine & $2.2 \pm 0.6$ & $2.6 \pm 8$ & $1.6 \pm 0.6$ & 0.21 \\
\hline Folic acid & $410 \pm 121$ & $304 \pm 41$ & $226 \pm 54$ & $<0.001$ \\
\hline Cobalamin & $4.7 \pm 2$ & $5 \pm 2$ & $4 \pm 2$ & 0.005 \\
\hline Ascorbic acid & $281 \pm 111$ & $181 \pm 50$ & $126 \pm 40$ & $<0.001$ \\
\hline Vitamin A & $1928 \pm 939$ & $1276 \pm 302$ & $887 \pm 335$ & $<0.001$ \\
\hline Vitamin E & $64 \pm 16$ & $69 \pm 19$ & $65 \pm 21$ & 0.06 \\
\hline Beta carotene & $1527 \pm 897$ & $904 \pm 291$ & $582 \pm 311$ & $<0.001$ \\
\hline Vitamin D & $1.4 \pm 1.5$ & $2.2 \pm 11$ & $0.9 \pm 1.3$ & 0.21 \\
\hline Selenium & $0.04 \pm 0.16$ & $0.48 \pm 5$ & $-0.01 \pm 0.17$ & 0.31 \\
\hline Zinc & $10 \pm 4$ & $10 \pm 6$ & $8 \pm 4$ & $<0.001$ \\
\hline Iron & $22 \pm 6$ & $25 \pm 49$ & $20 \pm 8$ & 0.39 \\
\hline Tea & $356 \pm 263$ & $324 \pm 316$ & $242 \pm 220$ & 0.002 \\
\hline Magnesium & $326 \pm 59$ & $267 \pm 35$ & $216 \pm 46$ & $<0.001$ \\
\hline Onion & $54 \pm 34$ & $40 \pm 27$ & $29 \pm 19$ & $<0.001$ \\
\hline Garlic & $1.9 \pm 0.17$ & $1.9 \pm 0.25$ & $2 \pm 0.002$ & 0.13 \\
\hline Fiber & $10 \pm 3$ & $7 \pm 2$ & $5 \pm 1$ & $<0.001$ \\
\hline Caffeine & $82 \pm 57$ & $83 \pm 127$ & $59 \pm 50$ & 0.03 \\
\hline Pepper & $10 \pm 7.3$ & $10 \pm 8.7$ & $8 \pm 8.5$ & 0.26 \\
\hline SAFA & $25 \pm 8$ & $27 \pm 14$ & $23 \pm 9$ & 0.02 \\
\hline
\end{tabular}




\begin{tabular}{|lllll|}
\hline \multicolumn{5}{|c|}{ Tertile of energy -energy adjusted DIP } \\
\hline PUFA & $40 \pm 9$ & $46 \pm 44$ & $39 \pm 11$ & 0.06 \\
\hline MUFA & $32 \pm 8$ & $47 \pm 146$ & $30 \pm 9$ & 0.21 \\
CHOL & $234 \pm 85$ & $263 \pm 93$ & $232 \pm 99$ & 0.01 \\
\hline
\end{tabular}

The mean \pm SD plasma levels of endothelial markers in different tertiles are shown in Table 3. There was no significant association between DIP and E-selectin in the crude model ( $P$-value $=0.35)$ compared to model I $(P$-value $=0.57)$, model II $(P$-value $=0.57)$ and model III $(P$-value $=0.67)$ after adjusting for potential confounders (Fig. 1). 
Table 3

Index of endothelial functions across tertile categories of dietary inflammatory potential.

\section{Tertile of energy- adjusted DIP}

$$
\mathrm{T} 1(\mathrm{n}=133) \quad \mathrm{T} 2(\mathrm{n}=136) \quad \mathrm{T} 3(\mathrm{n}=135) \quad \mathrm{P}_{\text {for trend }}{ }^{\mathrm{P}}
$$

\section{E-selectin (ng/L)}

\begin{tabular}{lllll} 
Crude & $81.6 \pm 4.5$ & $85.5 \pm 4.5$ & $93.7 \pm 4.5$ & 0.35 \\
\hline Model I & $80 \pm 5.6$ & $88 \pm 5.3$ & $80 \pm 6.0$ & 0.57 \\
\hline Model II & $79 \pm 5.6$ & $88 \pm 5.3$ & $81 \pm 6.1$ & 0.57 \\
\hline Model III & $79 \pm 5.7$ & $88 \pm 5.8$ & $82 \pm 6.7$ & 0.67
\end{tabular}

SICAM-1 (mg/L)

\begin{tabular}{lllll} 
Crude & $221 \pm 6.68$ & $211 \pm 6.63$ & $213 \pm 6.65$ & 0.83 \\
\hline Model I & $215 \pm 10.9$ & $225 \pm 10.2$ & $215 \pm 11.7$ & 0.98 \\
\hline Model II & $215 \pm 10.9$ & $225 \pm 10.4$ & $215 \pm 10.8$ & 0.98 \\
\hline Model III & $214 \pm 9.5$ & $213 \pm 9.6$ & $212 \pm 11.1$ & 0.92
\end{tabular}

SVCAM-1 (mg/L)

\begin{tabular}{lllll} 
Crude & $503 \pm 11.76$ & $482 \pm 11.63$ & $509 \pm 11.67$ & 0.49 \\
Model I & $479 \pm 23.2$ & $496 \pm 21.8$ & $515 \pm 25.3$ & 0.45 \\
\hline Model II & $478 \pm 23.1$ & $490 \pm 22.0$ & $516 \pm 25.2$ & 0.45 \\
\hline Model III & $477 \pm 24.3$ & $492 \pm 24.8$ & $502 \pm 28.9$ & 0.50
\end{tabular}

a) Values are mean $\pm S E$ in the tables and were compute by the use of ANCOVA.

b) Model I: adjusted for age, energy intake, physical activity (MET-h/wk), current corticoid steroids use (yes or no), current OCP use (yes or no), marital status (categorical), menopausal status (yes or no), systolic blood pressure, diastolic blood pressure, and socioeconomic status (categorical).

c) Model II: Further adjusted for BMI.

d) Model III: Further adjusted for blood lipids and glucose.

e) $p$-Value was calculated from linear regression of adhesion molecules on a categorical variable of dietary in index intake.

The results showed no significant association between DIP and the plasma level of sICAM- 1 in the crude model (P-value: 0.83) compared to model I (P-value: 0.98), model II (P-value: 0.98) and model III (P-value: 0.92) after adjusting for potential confounders (Fig. 2). 
In addition, no significant association was found between DIP and the plasma level of sVCAM-1 in the crude model compared to model I (P-value: 0.49), model II (P-value: 0.45) and model III (P-value: 0.50) after adjusting for potential confounders (Fig. 3).

\section{Discussion}

No association was observed between dietary inflammatory potential (DIP) and endothelial biomarkers including E-selectin, sVCAM-1 and sICAM-1 in the participants. This dissociation remained significant after adjusting for possible confounders. This is the first study of the association between adhesion molecules and DIP. Other studies assessed the correlation between DIP and cardiovascular disease.

Adhesion of circulating molecules, including E-selectin, sICAM-1 and SVCAM-1, plays an essential role in endothelial dysfunction and atherosclerosis [14, 35-39]. Furthermore, reactive oxygen species (ROS) activate endothelial markers by inducing E-selectin, sICAM-1 and sVCAM-1. It has been reported that sICAM-1 plays an important role as a predictor of CVD [40]. Moreover, the sVCAM-1 expression represents the inflammatory conditions of the vascular walls and predicts fatal coronary artery disease in the future $[39,41]$. Plasma levels of endothelial markers such as sE-selectin and SICAM-1 correlate with prognosis [11]. Many studies have assessed the correlation of DIP with CVD.

The results of the present study are consistent with a study by Imran khan et a/ who carried out a cohort study on 1111 subjects to evaluate the relationship between DIP and cardiovascular disease (CVD). The results showed no a significant correlation between DIP and CVD in females while a significant relationship was found in male subjects [42]. Similarly, Gabriela Pocovi-Gerardino et al conducted a crosssectional study on 105 women with a mean age of 45.4 years old and found no significant correlation between the DIP score and CVD markers [43]. A study of 585 women aged $50-55$ years old by Linda E. T. Vissers et al failed to show any correlation between DIP and CVD, ischemic heart disease, and myocardial infarction (MI) [44]. Furthermore, a prospective case-control study of 100000 participants showed no significant relationship between DII and MI [45].

By contrast, Bondonno et al reported that a high DIP score was associated with atherosclerotic vascular disease in women aged over 70 although they did not find any association between DIP and carotid plaque severity [46]. Moreover, Stefanos Tyrovolas et al carried out a dose-dependent study to assess the correlation between DIP and CVD risk factors. They found a significant correlation between DIP and CVD risk factors such as diabetes mellitus, obesity, hypertension, and hypercholesterolemia. In addition, the participants with a high DIP score in the 3rd and 4th quartile had at least one CVD risk factor in comparison to the participants in the 1st quartile [47].

It was difficult to sort out consistent results with our findings because many studies were carried out on subjects with unhealthy conditions. Moreover, there were differences between the studies in terms of the sample size. The geographic dietary pattern may also affect the results. Furthermore, many studies did not measure the plasma levels of sICAM-1, sVCAM-1 and E-selectin directly. Therefore, more studies are required to assess the correlation between endothelial markers and the DIP score. 
This study had some limitations. For example, it had a cross-sectional design and therefore no conclusions can be made regarding causality. Moreover, there were some unknown confounders including shift time, bias in reporting food items, and difference in the dietary pattern between nurses in private and public hospitals, which could affect the results. Studies with larger sample sizes are required to obtain concrete results.

\section{Conclusion}

In summary, the findings suggest that the plasma levels of endothelial markers including E-selectin, ICAM-1 and SVCAM-1 have no significant correlation with dietary inflammatory potential in females.

\section{Abbreviations}

SICAM-1

Soluble intercellular adhesion molecule-1; DIP:Dietary inflammatory potential; FFQ:Food frequency questionnaire; CVD:Cardiovascular disease; CAM:Cell adhesion molecules; IL-6:Interleukin 6; TNF-a:Tumor necrosis factor alpha; CRP:C-reactive protein; LDL:Low-density lipoprotein; HDL:High-density lipoprotein; SFA:Saturated fatty acids; MUFA:Monounsaturated fatty acids; PUFA:Polyunsaturated fatty acids; BMl:Body mass index; OCP:Oral contraceptive

\section{Declarations}

\section{Acknowledgments:}

The authors thank the Board of Directors of Isfahan Nursing Organization for this study. We are also thankful to the staff of Isfahan hospitals who contribute at this study. Also, we acknowledge the helps from Farzaneh Barak to collect data.

\section{Authors' contributions:}

The conception and design of the study performed by MG, ES, AS. Analysis and interpretation of data carried out by MG, AE and confirmed by AS. The collecting samples used to by MG, AH, AY, EF and PS. Manuscript wrote by MG, AE and revised by AS.

\section{Funding:}

This research supported by Isfahan University Medical Sciences, Lorestan University of Medical Sciences and Tehran University of Medical Sciences.

\section{Availability of data and materials:}

The data collected and analyzed during in current study. All data are available from professor Ahmad Esmaeilzadeh, Ahmad Saedisomeolia on reasonable request. 


\section{Declarations:}

\section{Ethics approval and consent to participate}

The study protocol was approved by Tehran university of medical sciences

(IR.TUMS.VCR.REC.1399.584).

\section{Consent for publication}

The participants fill in a consent form based on Tehran university of medical sciences ethics rules for participating on this study.

\section{Competing interests:}

The authors declare that they have no competing interests

\section{References}

1. Hansson GK, Robertson A-KL, Söderberg-Nauclér C. Inflammation and atherosclerosis. Annu Rev Pathol Mech Dis. 2006;1:297-329.

2. Hansson GK. Inflammation, atherosclerosis, and coronary artery disease. N Engl J Med. 2005;352(16):1685-95.

3. Tuttolomondo A, Di Raimondo D, Pecoraro R, Arnao V, Pinto A, Licata G. Atherosclerosis as an inflammatory disease. Curr Pharm Design. 2012;18(28):4266-88.

4. Libby P, Ridker PM, Maseri A. Inflammation and atherosclerosis. Circulation. 2002;105(9):1135-43.

5. Endemann DH, Schiffrin EL. Endothelial dysfunction. J Am Soc Nephrol. 2004;15(8):1983-92.

6. Constans J, Conri C. Circulating markers of endothelial function in cardiovascular disease. Clinica chimica acta. 2006;368(1-2):33-47.

7. Ajjan RA, Grant PJ. Cardiovascular disease prevention in patients with type 2 diabetes: The role of oral anti-diabetic agents. Diabetes Vascular Disease Research. 2006;3(3):147-58.

8. Kim J-a, Montagnani M, Koh KK, Quon MJ. Reciprocal relationships between insulin resistance and endothelial dysfunction: molecular and pathophysiological mechanisms. Circulation. 2006;113(15):1888-904.

9. Davignon J, Ganz P. Role of endothelial dysfunction in atherosclerosis. Circulation 2004, 109(23_suppl_1):III-27-32.

10. Johnson-Tidey RR, McGregor JL, Taylor PR, Poston RN. Increase in the adhesion molecule P-selectin in endothelium overlying atherosclerotic plaques. Coexpression with intercellular adhesion molecule1. Am J Pathol. 1994;144(5):952.

11. Tenaglia AN, Buda AJ, Wilkins RG, Barron MK, Jeffords PR, Vo K, Jordan MO, Kusnick BA, Lefer DJ. Levels of expression of P-selectin, E-selectin, and intercellular adhesion molecule-1 in coronary 
atherectomy specimens from patients with stable and unstable angina pectoris. The American journal of cardiology. 1997;79(6):742-7.

12. Vestweber D, Blanks JE. Mechanisms that regulate the function of the selectins and their ligands. Physiological reviews. 1999;79(1):181-213.

13. Ley K. Molecular mechanisms of leukocyte recruitment in the inflammatory process. Cardiovascular research. 1996;32(4):733-42.

14. Kozuka K, Kohriyama T, Nomura E, Ikeda J, Kajikawa H, Nakamura S. Endothelial markers and adhesion molecules in acute ischemic stroke-sequential change and differences in stroke subtype. Atherosclerosis. 2002;161(1):161-8.

15. Bouhlel M, Staels B, Chinetti-Gbaguidi G. Peroxisome proliferator-activated receptors-from active regulators of macrophage biology to pharmacological targets in the treatment of cardiovascular disease. Journal of internal medicine. 2008;263(1):28-42.

16. Abe Y, Sugisaki K, Dannenberg AM Jr. Rabbit vascular endothelial adhesion molecules: ELAM-1 is most elevated in acute inflammation, whereas VCAM-1 and ICAM-1 predominate in chronic inflammation. J Leukoc Biol. 1996;60(6):692-703.

17. Zhang J, Alcaide P, Liu L, Sun J, He A, Luscinskas FW, Shi G-P. Regulation of endothelial cell adhesion molecule expression by mast cells, macrophages, and neutrophils. PloS one. 2011;6(1):e14525.

18. Varki A: Selectin ligands. Proceedings of the National Academy of Sciences 1994, 91(16):73907397.

19. Collins RG, Velji R, Guevara NV, Hicks MJ, Chan L, Beaudet AL. P-selectin or intercellular adhesion molecule (ICAM)-1 deficiency substantially protects against atherosclerosis in apolipoprotein Edeficient mice. The Journal of experimental medicine. 2000;191(1):189-94.

20. Takahashi K, Takeya M, Sakashita N. Multifunctional roles of macrophages in the development and progression of atherosclerosis in humans and experimental animals. Medical electron microscopy. 2002;35(4):179-203.

21. Shivappa N, Steck SE, Hurley TG, Hussey JR, Hébert JR. Designing and developing a literaturederived, population-based dietary inflammatory index. Public Health Nutr. 2014;17(8):1689-96.

22. Cavicchia PP, Steck SE, Hurley TG, Hussey JR, Ma Y, Ockene IS, Hébert JR. A new dietary inflammatory index predicts interval changes in serum high-sensitivity C-reactive protein. J Nutr. 2009;139(12):2365-72.

23. Shivappa N, Steck SE, Hurley TG, Hussey JR, Ma Y, Ockene IS, Tabung F, Hébert JR. A populationbased dietary inflammatory index predicts levels of C-reactive protein in the Seasonal Variation of Blood Cholesterol Study (SEASONS). Public Health Nutr. 2014;17(8):1825-33.

24. Wirth M, Burch J, Shivappa N, Violanti JM, Burchfiel CM, Fekedulegn D, Andrew ME, Hartley TA, Miller DB, Mnatsakanova A. Association of a dietary inflammatory index with inflammatory indices and the metabolic syndrome among police officers. Journal of occupational environmental medicine/American College of Occupational Environmental Medicine. 2014;56(9):986. 
25. Wood LG, Shivappa N, Berthon BS, Gibson PG, Hebert JR. Dietary inflammatory index is related to asthma risk, lung function and systemic inflammation in asthma. Clinical Experimental Allergy. 2015;45(1):177-83.

26. García-Calzón S, Zalba G, Ruiz-Canela M, Shivappa N, Hébert JR, Martínez JA, Fitó M, Gómez-Gracia E, Martínez-González MA, Marti A. Dietary inflammatory index and telomere length in subjects with a high cardiovascular disease risk from the PREDIMED-NAVARRA study: cross-sectional and longitudinal analyses over 5 y. Am J Clin Nutr. 2015;102(4):897-904.

27. Neufcourt L, Assmann K, Fezeu L, Touvier M, Graffouillère L, Shivappa N, Hébert J, Wirth M, Hercberg $\mathrm{S}$, Galan P. Prospective association between the dietary inflammatory index and metabolic syndrome: Findings from the SU. VI. MAX study. Nutrition Metabolism Cardiovascular Diseases. 2015;25(11):988-96.

28. Tabung FK, Steck SE, Zhang J, Ma Y, Liese AD, Agalliu I, Hingle M, Hou L, Hurley TG, Jiao L. Construct validation of the dietary inflammatory index among postmenopausal women. Ann Epidemiol. 2015;25(6):398-405.

29. Namazi N, Larijani B, Azadbakht L. Dietary inflammatory index and its association with the risk of cardiovascular diseases, metabolic syndrome, and mortality: A systematic review and meta-analysis. Horm Metab Res. 2018;50(05):345-58.

30. Ruiz-Canela M, Bes-Rastrollo M, Martínez-González MA. The role of dietary inflammatory index in cardiovascular disease, metabolic syndrome and mortality. Int J Mol Sci. 2016;17(8):1265.

31. Asadi Z, Yaghooti-Khorasani M, Ghazizadeh H, Sadabadi F, Mosa-Farkhany E, Darroudi S, Shabani N, Kamel-khodabandeh A, Bahrami A, Khorrami-Mohebbseraj MS. Association between dietary inflammatory index and risk of cardiovascular disease in the Mashhad stroke and heart atherosclerotic disorder study population. IUBMB Life. 2020;72(4):706-15.

32. Willett W, Stampfer MJ. Total energy intake: implications for epidemiologic analyses. Am J Epidemiol. 1986;124(1):17-27.

33. Booth M. Assessment of physical activity: an international perspective. Res Q Exerc Sport. 2000;71(sup2):114-20.

34. Committee IR. Guidelines for data processing and analysis of the International Physical Activity Questionnaire (IPAQ)-short and long forms. http://www ipaq ki se/scoring pdf 2005.

35. Hwang S-J, Ballantyne CM, Sharrett AR, Smith LC, Davis CE, Gotto AM Jr, Boerwinkle E. Circulating adhesion molecules VCAM-1, ICAM-1, and E-selectin in carotid atherosclerosis and incident coronary heart disease cases: the Atherosclerosis Risk In Communities (ARIC) study. Circulation. 1997;96(12):4219-25.

36. Ridker PM, Hennekens CH, Roitman-Johnson B, Stampfer MJ, Allen J. Plasma concentration of soluble intercellular adhesion molecule 1 and risks of future myocardial infarction in apparently healthy men. The Lancet. 1998;351(9096):88-92.

37. de Lemos JA, Hennekens $\mathrm{CH}$, Ridker PM. Plasma concentration of soluble vascular cell adhesion molecule-1 and subsequent cardiovascular risk. J Am Coll Cardiol. 2000;36(2):423-6. 
38. Ridker PM, Buring JE, Rifai N. Soluble P-selectin and the risk of future cardiovascular events. Circulation. 2001;103(4):491-5.

39. Malik I, Danesh J, Whincup P, Bhatia V, Papacosta O, Walker M, Lennon L, Thomson A, Haskard D. Soluble adhesion molecules and prediction of coronary heart disease: a prospective study and metaanalysis. The Lancet. 2001;358(9286):971-5.

40. Luc G, Arveiler D, Evans A, Amouyel P, Ferrieres J, Bard J-M, Elkhalil L, Fruchart J-C, Ducimetiere P, Group PS. Circulating soluble adhesion molecules ICAM-1 and VCAM-1 and incident coronary heart disease: the PRIME Study. Atherosclerosis. 2003;170(1):169-76.

41. Blankenberg S, Rupprecht HJ, Bickel C, Peetz D, Hafner G, Tiret L, Meyer Jr, Investigators A. Circulating cell adhesion molecules and death in patients with coronary artery disease. Circulation. 2001;104(12):1336-42.

42. Khan I, Kwon M, Shivappa N, Hébert JR, Kim MK. Positive Association of Dietary Inflammatory Index with Incidence of Cardiovascular Disease: Findings from a Korean Population-Based Prospective Study. Nutrients. 2020;12(2):588.

43. Pocovi-Gerardino G, Correa-Rodríguez M, Callejas-Rubio J-L, Ríos-Fernández R, Martín-Amada $M$, Cruz-Caparros M-G, Rueda-Medina B, Ortego-Centeno N. Dietary Inflammatory Index Score and Cardiovascular Disease Risk Markers in Women with Systemic Lupus Erythematosus. Journal of the Academy of Nutrition Dietetics. 2020;120(2):280-7.

44. Vissers LE, Waller MA, van der Schouw YT, Hebert JR, Shivappa N, Schoenaker DA, Mishra GD. The relationship between the dietary inflammatory index and risk of total cardiovascular disease, ischemic heart disease and cerebrovascular disease: Findings from an Australian population-based prospective cohort study of women. Atherosclerosis. 2016;253:164-70.

45. Bodén S, Wennberg M, Van Guelpen B, Johansson I, Lindahl B, Andersson J, Shivappa N, Hebert JR, Nilsson LM. Dietary inflammatory index and risk of first myocardial infarction; a prospective population-based study. Nutrition journal. 2017;16(1):21.

46. Bondonno NP, Lewis JR, Blekkenhorst LC, Shivappa N, Woodman RJ, Bondonno CP, Ward NC, Hébert $\mathrm{JR}$, Thompson PL, Prince RL. Dietary inflammatory index in relation to sub-clinical atherosclerosis and atherosclerotic vascular disease mortality in older women. Br J Nutr. 2017;117(11):1577-86.

47. Tyrovolas S, Koyanagi A, Kotsakis GA, Panagiotakos D, Shivappa N, Wirth MD, Hebert JR, Haro JM. Dietary inflammatory potential is linked to cardiovascular disease risk burden in the US adult population. Int J Cardiol. 2017;240:409-13.

\section{Figures}




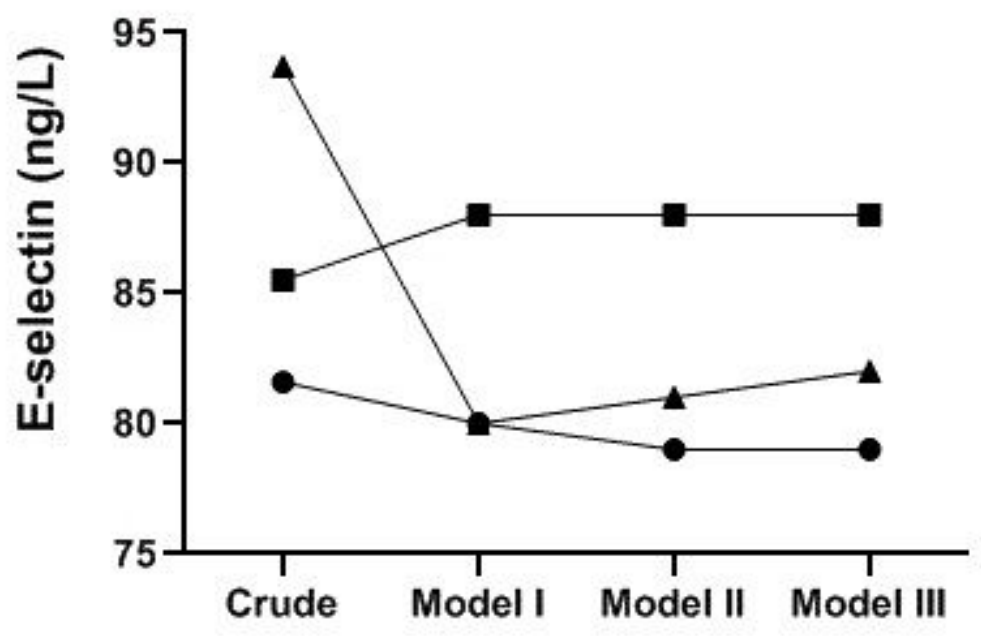

$\bullet$ Tertile $_{1}$

- Tertile $_{2}$

^ Tertile 3

Figure 1

The E-selectin plasma concentration in tertiles (mean \pm SEM)

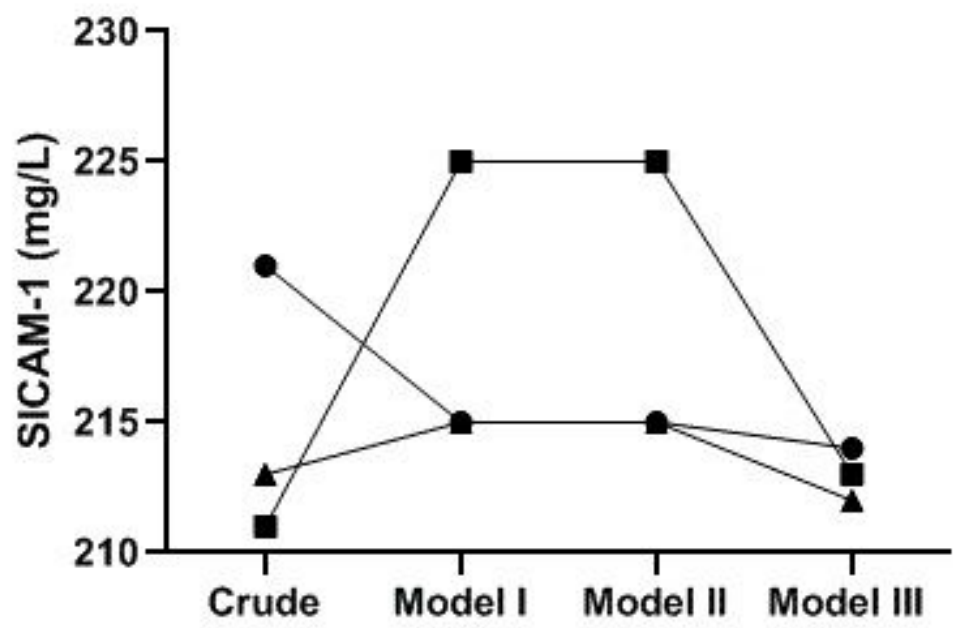
$\bullet$ Tertile $_{1}$
$\rightarrow$ Tertile $_{2}$
$\star$ Tertile $_{3}$

Figure 2

The ICAM-1 plasma concentration in tertiles (mean \pm SEM) 


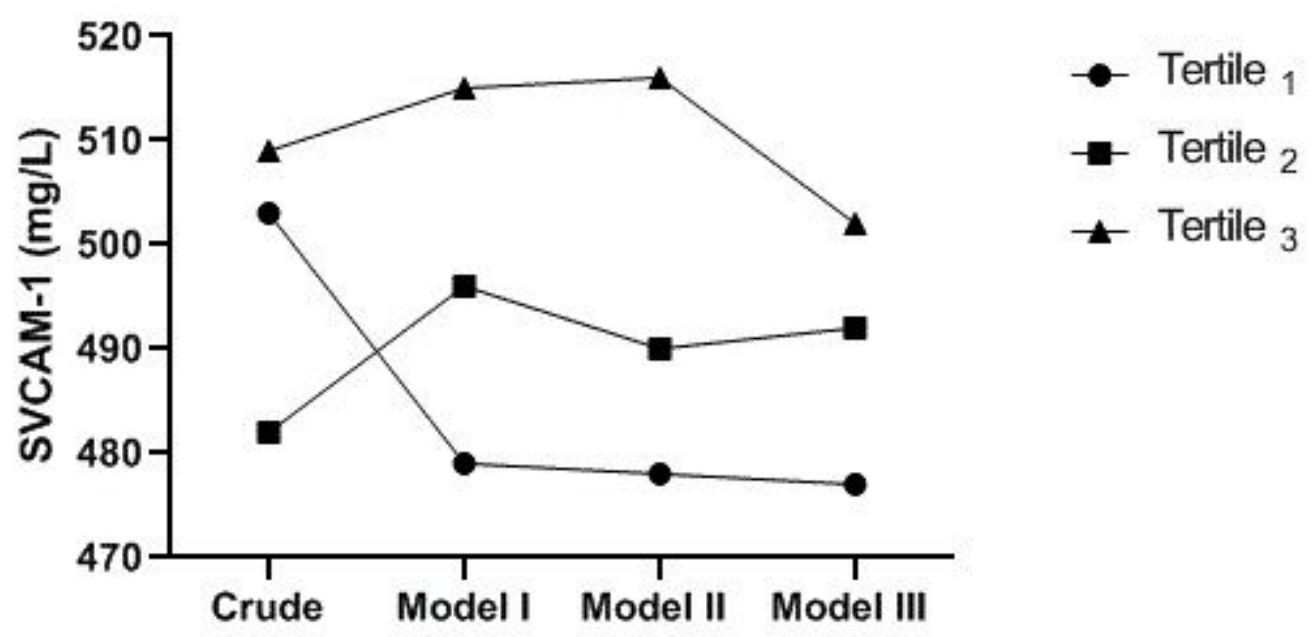

Figure 3

The sVCAM-1 plasma concentration in tertiles (mean \pm SEM)

\section{Supplementary Files}

This is a list of supplementary files associated with this preprint. Click to download.

- Graphicalabstract.tif 